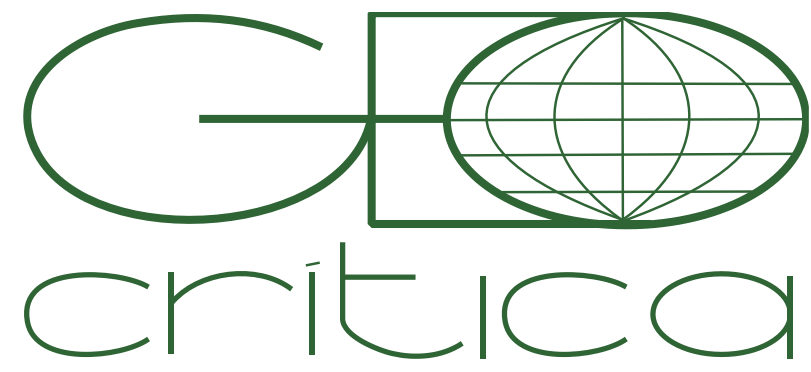

\section{Scripta Nova}

Revista Electrónica de Geografía y Ciencias Sociales Universitat de Barcelona

ISSN: 1138-9788

Vol. 25, Núm. 1 (2021), p. 59-81

\title{
O COMPLEXO IMOBILIÁRIO/FINANCEIRO NO BRASIL E NA ITÁLIA: FERRAMENTAS PARA A PRODUÇÃO FINANCEIRIZADA DO ESPAÇO URBANO
}

\author{
Mayra Mosciaro \\ University of Amsterdam \\ m.ribeiromosciaro@uva.nl
}

Recibido: 5 septiembre 2020; Devuelto para correcciones: 5 octubre 2020; Aceptado: 28 octubre 2020.

\section{O complexo imobiliário/financeiro no Brasil e na Itália: ferramentas para a produção} financeirizada do espaço urbano (Resumo)

A rápida propagação da crise habitacional norte-americana em uma crise global chamou atenção para o estreitamento das relações entre os setores imobiliário, financeiro e os estados. Diante da ausência de estudos que investigassem essas três esferas, Aalbers (2011) propôs a ideia de um Real Estate/Financial Complex, ou Complexo Imobiliário/Financeiro. O intuito desse conceito é não apenas abarcar esses três atores em uma análise macro (escala nacional), mas também observar na escala local como essas relações se manifestam no tecido urbano. Este artigo desvenda os traços desse Complexo nos casos do Brasil e da Itália, demonstrando como as Operações Urbanas e os Programas de Intervenção Integrada são representativos do processo de financeirização do ambiente construído nesses países.

Palavras-chave: financeirização; REFCOM; Brasil; Itália; grandes projetos urbanos.

The real estate / financial complex in Brazil and Italy: tools for the financial production of urban space (Abstract)

The rapid spread of the North American housing crisis in a global crisis drew attention to the connections between the real estate, financial sectors and the states. In the absence of studies that bring together these three spheres, Aalbers (2011) proposed the idea of a Real Estate / Financial Complex. The purpose of this concept is not only to encompass these three actors in a macro analysis (national scale), but also to observe on the local level how these relationships are manifested in the urban fabric. This article reveals the features of this Complex in the cases of Brazil and Italy, demonstrating how Urban Operations and Integrated Intervention Programs are representative of the process of built environment financialization in these countries.

Keywords: financialization; REFCOM; Brazil; Italy; urban redevelopment programs. 
Desde a eclosão da crise Norte Atlântica, também chamada de Crise Financeira Global, em 2007/08, debates sobre a financeirização do mercado imobiliário se popularizaram. Financeirização não é um conceito novo per se, Arrighi (1994) já utilizava o termo para chamar atenção para um novo ciclo de acumulação capitalista no qual o lucro é obtido por meios financeiros, em detrimento da produção e comercialização de bens. Na época, Arrighi definiu os anos 80 como "a década da financeirização", no entanto essa ideia parece ainda mais contemporânea hoje. Os drásticos impactos da crise no setor residencial de alguns países serviram para trazer à tona as transformações que vêm ocorrendo e se intensificando ao longo dos últimos anos em todo o mundo (Aalbers and Fernandez 2019).

Apesar das hipotecas subprime norte-americanas ou das hipotecas espanholas terem se tornado o maior exemplo deste processo, esses casos são apenas a ponta do iceberg. Primeiramente, é importante esclarecer que não são apenas esses países que estão sujeitos à financeirização dos seus mercados residenciais. Estudos em diferentes partes do mundo já evidenciam uma trajetória comum - crescentes níveis de endividamento pessoal; o "boom" da casa própria em diferentes grupos socais, inclusive os mais vulneráveis; e novos instrumentos para flexibilizar e tornar mais líquidos os investimentos no mercado imobiliário (securitização, fundos de investimento imobiliário, etc.) (Fernandez 2017). Em segundo lugar, é ainda mais importante esclarecer que esses instrumentos que transformam bens imobiliários em "ativos financeiros" não estão restritos ao mercado habitacional; todos os nichos do mercado imobiliário estão sujeitos a essas práticas (residencial, comercial, infraestrutura e grandes projetos urbanos) (Britto and Rezende 2017). Desta forma, a financeirização do ambiente construído é um fenômeno presente na vida de milhões de pessoas, mesmo aquelas que não possuem uma hipoteca, não dependem de empréstimos para a aquisição do seu imóvel, não moram em países com setores residenciais altamente financeirizados, etc. Por esse motivo, levando em consideração países como o Brasil e a Itália, que ainda possuem pequenos índices de financeirização do mercado residencial, outros caminhos para identificar, analisar e compreender o Complexo Imobiliário/Financeiro foram implementados.

Este artigo foi dividido em cinco sessões. Na primeira iremos definir como entendemos financeirização, apresentando alguns debates sobre a crescente popularização deste conceito. Em seguida, apresentaremos a ideia de Real Estate/Financial Complex (REFCOM, literalmente traduzido como Complexo Imobiliário/Financeiro) como compreendida por Aalbers (2011). Apresentaremos também o grupo de pesquisa homônimo, posicionando este artigo dentro da estrutura do REFCOM. A terceira sessão irá introduzir dois instrumentos de planejamento urbano, um brasileiro e um italiano, que têm facilitado a infiltração de práticas financeirizadas no ambiente construído (Aalbers and Fernandez 2019) desses países. Nós apoiaremos em dois estudos de caso, a Operação Urbana Porto Maravilha (Rio de Janeiro) e o CityLife (Milão), para ilustrar esse fenômeno. Por fim, discutiremos como 
as experiências dessas cidades não são exceções, contribuindo para uma literatura mais plural e menos anglófona sobre a financeirização das cidades e a constituição do Complexo Imobiliário/Financeiro.

\section{Financeirização}

Apesar da afirmação de Arrighi (1994) de que os anos 80 foram a década da financeirização, na literatura acadêmica esse conceito só ganhou momentum nos anos 2000, em especial após 2007. Ioannou e Wójcik (2018) identificaram mais de sete mil artigos que mencionam o termo financialization ou financialisation, apenas em 2016. Fazendo a mesma pesquisa no Google Acadêmico com a palavra em português, percebemos que 2017 foi o "ano da financeirização": 1910 artigos, um aumento de mais de $200 \%$ em comparação com $2010^{1}$. Assim, o aumento exponencial de artigos sobre o tema coloca-o lado-a-lado com outras palavras da moda (buzzwords), como "globalização" e "neoliberalismo", levantando críticas sobre o seu uso indiscriminado.

Segundo a perspetiva de Christophers (2015), o uso excessivo do conceito acaba por torná-lo vazio, pouco esclarecedor e muito abrangente. Porém, para nós, esta abrangência é um de seus pontos fortes (Aalbers 2015; Fairbairn 2015). A crescente utilização do conceito, de acordo com Engelen (2008), pode ser atribuída a novas observações empíricas que não encontram respostas em conceitos preexistentes. Trata-se de adotar um novo termo para descrever e aglutinar processos que até recentemente eram pouco explorados pela literatura acadêmica. Nesse processo de consolidação, financeirização acabou por estabelecer-se como um termo multidisciplinar e capaz de atuar de duas formas, seja como um fenômeno a ser explicado (explanandum), seja como um conceito que auxilia na explicação de um fenômeno (explanans) (Aalbers 2015).

Ademais, a difusão deste tópico pode ser relacionada com a popularização da subdisciplina geografia financeira. Este nicho do conhecimento geográfico não visa simplesmente identificar onde estão os maiores centros financeiros do mundo ou quais são as suas funções e impactos na economia global. Primordialmente, a geografia financeira visa compreender como as finanças têm mudado as relações socio espaciais em diferentes contextos e diferentes escalas. Trata-se de usar a ascensão do mercado financeiro (suas lógicas, racionalidades e narrativas) como uma lente para compreender mudanças em diversos setores das sociedades contemporâneas (Aalbers 2017).

A ideia de mudança está muito presente em estudos sobre financeirização. Em seu artigo sobre o futuro desse conceito, Ioannou e Wójcik (2018) não questionam a sua popularização como um aspecto negativo, mas demandam a manutenção de um rigor teórico para o seu uso. Sendo assim, é imprescindível esclarecer que financeirização é entendida aqui como "o crescente domínio de atores financeiros, mercados, práticas,

1 https://scholar.google.com.br/, acessado em 20 de janeiro de 2019. 
medidas e narrativas, em várias escalas, resultando na transformação estrutural das economias, empresas (incluindo instituições financeiras), estados e famílias" (Aalbers 2017 - tradução nossa). A opção por essa definição se dá por conta da sua abrangência conceitual, que inclui diversos sinais do que significa financeirização e permite estudar casos pouco comuns na literatura existente, maioritariamente anglófona.

O foco deste artigo é a financeirização do ambiente construído nos contextos do Brasil e da Itália e a investigação da estrutura dos seus Complexos Imobiliário/Financeiros. Complementando e especificando ainda mais o que se busca discutir aqui, pode-se mencionar a sucinta descrição de Lake (2016) da financeirização das cidades: "no âmbito da política urbana, a financeirização se refere à reimaginação, redireccionamento, redesenho e implementação da governança urbana como uma prática dirigida pela lógica do instrumento de financiamento, em vez de uma prática orientada pelas necessidades sociais e econômicas dos residentes urbanos" (p. 53 tradução nossa).

Sendo assim, nas próximas sessões iremos apresentar dois instrumentos de planejamento urbano aplicados no Brasil e na Itália que facilitam e estimulam a reconfiguração da governança urbana, em prol de atores, narrativas, instrumentos e métricas provenientes do mercado financeiro. Apesar de se tratar de um volume sobre casos latino-americanos, o contraponto com a Itália nos permite demonstrar dois caminhos distintos para a financeirização do espaço urbano. Além disso, dentro da estrutura do grupo de pesquisa REFCOM esses casos foram analisados conjuntamente. Antes de discutirmos os casos das Operações Urbanas (Brasil) e dos Programas de Intervenção Integrada (Itália), como parte fundamental do Complexo Imobiliário/Financeiro nesses países, devemos introduzir o conceito e a pesquisa realizada por trás do Real Estate/Financial Complex.

\section{"The Real Estate/Financial Complex"”}

O conceito de Real Estate/Finacial Complex (REFCOM), traduzido para "Complexo Imobiliário/Financeiro" (Rolnik 2015), foi introduzido por Aalbers como uma analogia ao complexo Militar/Industrial mencionado pelo presidente norte-americano Eisenhower nos anos 60 (Aalbers 2011). Tal analogia visava chamar atenção para as relações que se forjaram ao longo da segunda metade do século XX e a primeira década do século XXI entre o mercado imobiliário, o estado e o mercado financeiro. Os impactos da crise habitacional norte-americana trouxeram à tona debates referentes à comodificação do ambiente construído. No entanto, a rápida propagação dessa crise, inicialmente local, em uma crise global, demonstrou que tais relações iam muito além dos Estados Unidos e precisavam ser estudadas numa perspetiva internacional.

O conceito proposto por Aalbers (2011) é pautado por uma perspetiva interdisciplinar e multiescalar. Como mencionado no projeto de pesquisa intitulado

2 Site do grupo de pesquisa REFCOM

https://ees.kuleuven.be/geography/projects/refcom/project/index.html, acessado em 28.01.2019 
The Real Estate/Financial Complex, estudos da economia tradicional focam excessivamente em modelos abstratos, pouco assimilados por cientistas sociais, e frequentemente pró-mercado e anti-Estado. Na ciência política, pesquisadores tendem a considerar a análise entre estado e finanças, porém deixam de lado o mercado imobiliário. Por fim, as diferentes disciplinas dos estudos urbanos tendem a não valorizar o setor financeiro como uma importante variável na formação de cidades. Além disso, os estudos urbanos têm uma tradição de realizar pesquisas em microescala, enquanto as várias tradições da economia política são focadas em uma perspetiva macro. Em outras palavras, não precisamos apenas de uma conexão mais forte entre finanças e mercado imobiliário, mas também entre diferentes escalas: local/urbana, nacional/global (Aalbers, 2011). Com o intuito de responder a essa lacuna na literatura internacional o grupo de pesquisa REFCOM foi formado.

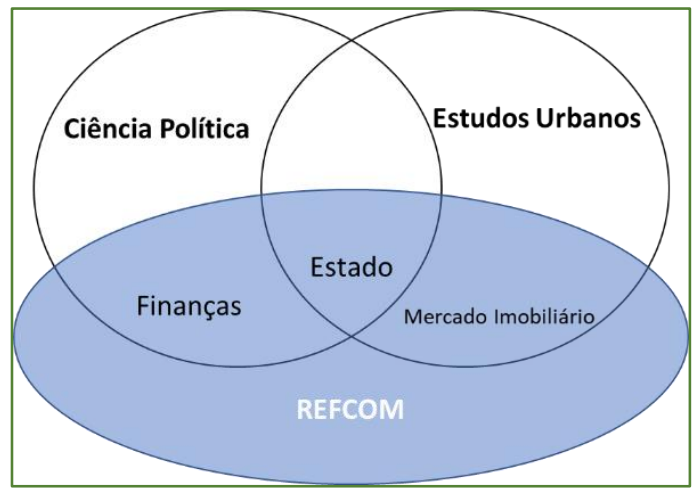

Figura 1: Representação esquemática do REFCOM.

Fonte: https://ees.kuleuven.be/geography/projects/refcom/project/index.html

O grupo investigou onze países, por meio de estudos comparativos, a fim de identificar a ocorrência (ou não) de mercados imobiliários financeirizados e os seus traços em cada um desses contextos (Fernandez 2017). Os países que compõem o projeto são: Rússia/Polônia (Büdenbender 2017), Holanda/Bélgica (van Loon 2017), Estados Unidos/Reino Unido (Hofman 2017), China/Hong Kong (Zhang 2018), Alemanha/França (Wijburg 2018) e Brasil/Itália (Mosciaro 2018). Como pressuposto pelo conceito de REFCOM, todos esses casos foram estudados em uma perspetiva interdisciplinar e multiescalar, analisando não apenas o contexto nacional, mas também as repercussões locais da financeirização do mercado imobiliário em seus diversos nichos (residencial, comercial, infraestrutura e grandes projetos urbanos). 


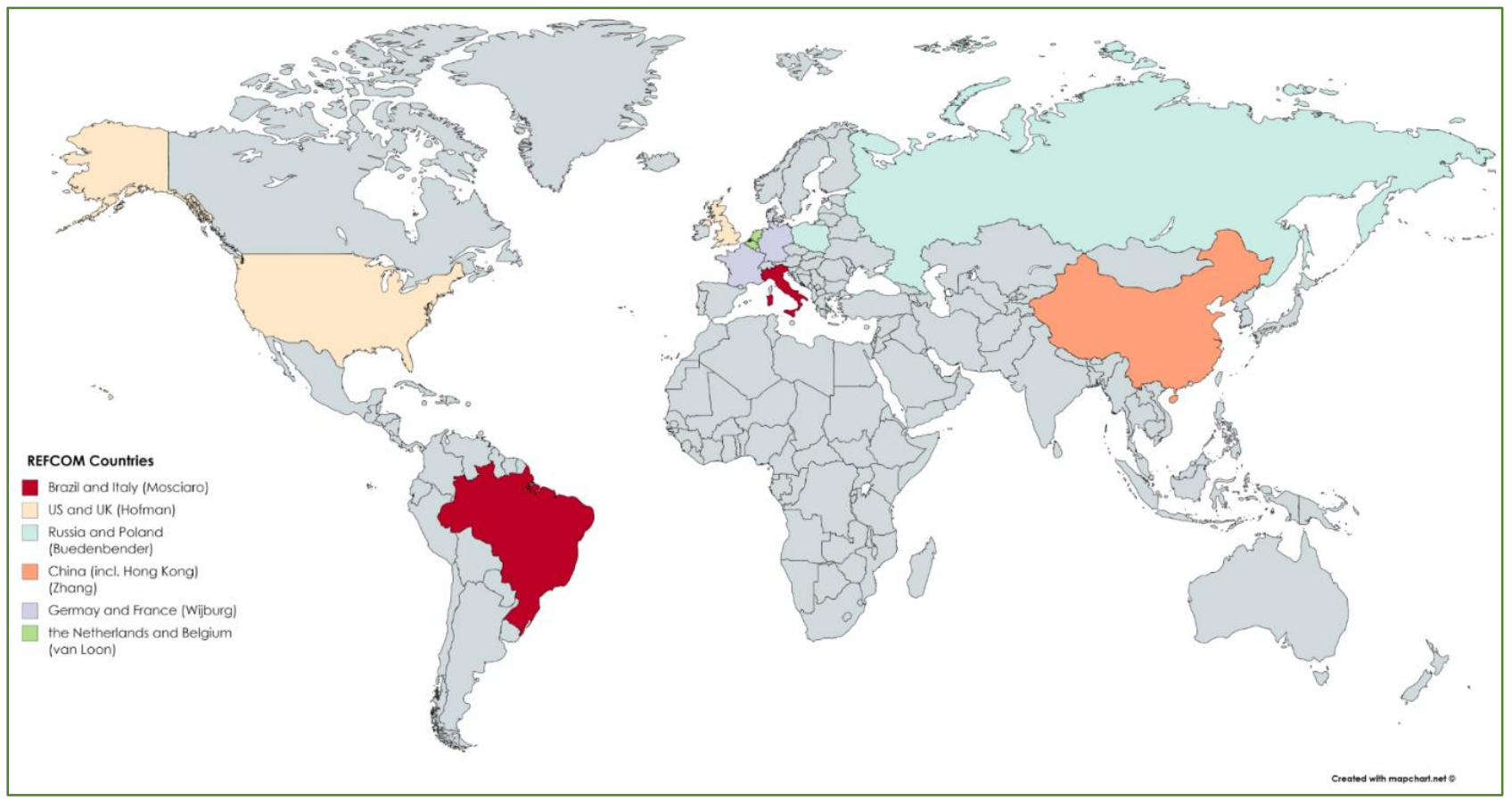

Figura 2: Países estudados pelo grupo de pesquisa REFCOM/KU Leuven

Fonte: Elaboração própria

Metodologicamente, todos os casos foram baseados em análises bibliográficas associadas a frequentes visitas de campo e entrevistas semi-estruturadas. As idas a campo tinham dois objetivos básicos. Em primeiro lugar, identificar as ferramentas e os atores que permitiram a infiltração de práticas financeirizadas nesses países (nacional - macro escala). E, posteriormente, investigar a fundo um exemplo de como essas práticas estão de fato impactando a produção de espaços urbanos (local microescala). No caso do Brasil e da Itália fizemos diversas visitas de campo entre 2013 e 2016, e parte das descobertas realizadas nesses anos será apresentada neste artigo. Em ambos os casos especialistas do setor privado, assim como funcionários públicos, foram entrevistados. Esses agentes foram peças-chave para esta pesquisa, pois o foco era compreender o funcionamento e a racionalidade nos quais se apoiam esses instrumentos que favorecem a produção financeirizada do ambiente construído.

Diferentes aspetos do mercado imobiliário foram analisados pelos membros do grupo de pesquisa. Cada estudo de caso foi selecionado levando em consideração as peculiaridades locais do mercado imobiliário e do seu processo de financeirização. Afinal, a "cultura das finanças" não é simplesmente formada por sistemas financeiros, ela também é influenciada por ideias e atores maioritariamente locais (Weber 2010). Tendo esse preceito como base, os integrantes do REFCOM puderam escolher livremente qual nicho do mercado imobiliário melhor representava esse processo nos seus estudos de caso, ou quais nichos haviam sido negligenciados pela literatura já existente. A proposta de estudar os casos do Brasil e da Itália se mostrava um grande desafio, visto que nesses dois países (em especial na Itália) o debate sobre financeirização do ambiente construído era ainda incipiente. Mesmo assim, diferentes 
sinais da infiltração de práticas financeirizadas nesses dois contextos foram identificados.

Durante as entrevistas realizadas na primeira fase desse projeto de pesquisa buscamos identificar quais exemplos eram percebidos pelos agentes locais como emblemáticos do processo de financeirização do ambiente construído em curso nesses países. Curiosamente, nas duas cidades escolhidas, Rio de Janeiro e Milão, havia um debate sobre dois grandes projetos urbanos. Tanto a "revitalização" da área portuária do Rio de Janeiro, como a transferência da Fiera de Milão são intervenções debatidas desde os anos 80, mas até recentemente não havia deslanchado (Andreatta 2010; Bellaviti 1994). Nos anos 2000, graças ao boom nacional e internacional do mercado imobiliário e a instrumentos criados na década anterior, que facilitariam a criação de Parcerias Público-Privadas (PPPs), foi possível tirar esses projetos do papel. Apesar de muito já ter sido discutido sobre esses dois casos (a necessidade de requalificar essas áreas, os aspetos arquitetónicos dos novos projetos, o impacto social nos bairros vizinhos, a "modernidade" trazida pelos novos empreendimentos e usuários, para mencionar apenas alguns tópicos) pouco havia sido escrito sobre a sua relação com mercados financeiros e sobre como podem ser compreendidos como a materialização do REFCOM.

A opção por comparar Brasil e Itália talvez seja a mais inusitada dentre os pares de estudos de caso que compõem o grupo de pesquisa. Porém, a inclusão desses países responde a uma demanda do projeto original (que já os mencionava como áreas de interesse (Aalbers 2011)) e da literatura internacional por mais casos que extrapolem exemplos do norte da Europa ou dos Estados Unidos (Fernandez and Aalbers 2016; Lapavitsas and Powell 2013). Esta composição representa dois caminhos que a financeirização do setor imobiliário assumiu em contextos ( semi-) periféricos, isto é, um país sul-americano e um do sul da Europa. Brasil e Itália compartilham muitos dos motores que desencadearam seus processos de crescente financeirização. Ambos sofreram pressões externas para "modernizar" e "liberalizar" suas economias, o que impactou fortemente em diversos setores, incluindo o bancário e o imobiliário (Mosciaro 2018). No entanto, como ocorre em todos os contextos, as peculiaridades, instituições e agências locais moldaram e orientaram essas transformações, produzindo casos de financeirização localmente configurados.

Dois desafios ao conduzir estudos de caso são conscientemente evitados neste artigo (Peck 2015). O primeiro é a ideia de que as cidades estão posicionadas em contraste com um caso "dominante", muitas vezes entendido como um caso do "Norte". Rio de Janeiro e Milão, Operações Urbanas e Programas de Intervenção Integrada, não serão contrastados com contextos considerados dominantes. Tampouco, faremos uma comparação que rotule um caso como dominante em relação ao outro. O objetivo deste estudo comparativo e da ideia de REFCOM como um todo é contribuir para uma teoria mais pluralista e diversificada dos estudos urbanos, e não posicionar essas experiências como anomalias ou reproduções diretas de práticas dos países desenvolvidos. 
A segunda questão abordada por Peck (2015) diz respeito à ideia de estudos urbanos cujos casos são frequentemente descritos como exceções. Os projetos urbanos aqui investigados não são excecionais. Pelo contrário, eles são a materialização local de práticas que ocorrem em todo o mundo. Afinal, a intenção dessa comparação é dialogar com uma literatura mais ampla, o que significa que os tópicos aqui abordados serão relacionáveis e identificáveis em uma variedade de contextos, contribuindo para o escopo dos estudos urbanos (Kantor and Savitch 2005).

Em suma, os casos do Brasil/Itália, das Operações Urbanas/Programas de Intervenção Integrada, têm o mérito de contribuir para a diversificação e ampliação da literatura sobre financeirização imobiliária e estudos urbanos em geral. Como observado por Kantor e Savitch (2005), poucos estudos comparativos tendem a ultrapassar as fronteiras nacionais e, mesmo quando isso acontece, raramente divergem das comparações anglo-americanas. Além disso, eles também enfatizam que "muitos estudiosos que realizam estudos comparativos não se aventuram nas cidades" (Kantor e Savitch, 2005, p. 136 - tradução nossa). Sendo assim, essa seleção de casos responde não somente à demanda por mais estudos de casos "periféricos" de financeirização imobiliária, mas também à demanda por mais estudos comparativos entre cidades (Peck 2015; Robinson 2010; Vainer 2014). Tendo posicionado os casos do Brasil e da Itália no contexto da pesquisa REFCOM, podemos na próxima sessão apresentar as legislações urbanísticas que facilitam a infiltração de práticas financeirizadas em duas das principais cidades desses países.

\section{Ferramentas para a financeirização do ambiente construído}

Apesar das hipotecas terem se tornado o mais simbólico e conhecido ícone da intensificação das relações entre os mercados financeiro e imobiliário, elas não representam o único caminho para que interesses e narrativas financeiras se infiltrem no setor. Na realidade, poucos são os países que possuem altíssimos níveis de financeirização dos seus mercados residenciais, embora esse volume esteja crescendo ao redor do mundo (Fernandez and Aalbers 2019). Nesse sentido, os exemplos ainda tímidos de financeirização do ambiente construído no Brasil e na Itália não significam que essas práticas não existam (De Gaspari 2010; Di Feliciantonio 2016; Sanfelici 2013).

Um aspecto que se demonstrava mais promissor e ainda assim pouco estudado nesses países são as recentes legislações de planejamento urbano, aprovadas nos anos 90 e 2000, e que hoje se tornaram veículos para a promoção de espaços urbanos financeirizados - as Operações Urbanas (OUs), no Brasil, e os Programas Integrados de Intervenção (PIIs), na Itália. Primeiramente, apresentaremos em linhas gerais os dois instrumentos que identificamos como cruciais para a financeirização de grandes projetos urbanos nesses países. Posteriormente, discutiremos quais aspectos nos levam a apontar esses mecanismos como indutores da financeirização do ambiente construído. Neste segundo estágio, utilizaremos como exemplo dois projetos de requalificação urbana. O primeiro, a Operação Urbana Porto Maravilha, que visa requalificar 5 milhões de m2 adjacentes à área central do Rio de Janeiro. Seguindo os 
preceitos da OU, esse projeto é supostamente financiado por meio da venda de títulos (CEPACs) no mercado, mas foi efetivamente custeado pela compra direta desses títulos por um fundo paraestatal, o FGTS. O segundo caso é o projeto milanês CityLife, totalmente controlado e financiado por agentes privados. Neste caso, empresas de seguros, em busca de novos bens para os seus portfólios, se tornaram construtores e promotores imobiliários. Embora essa breve descrição apresente contextos bastante distintos, ao longo deste artigo iremos demonstrar como esses casos podem ser percebidos como exemplos emblemáticos do Complexo Imobiliário/Financeiro nesses países.

\section{Operações Urbanas}

A Operação Urbana é um instrumento desenvolvido para fomentar e estimular projetos de requalificação no Brasil. O uso crescente, mas ainda limitado, desse mecanismo representa uma mudança em direção a um novo tipo de governança urbana, muito mais dependente de estratégias empreendedoras (Hall and Hubbard 1996; Harvey 1989). O Estatuto da Cidade, de 2001, introduz e regula uma série de novas ferramentas, dentre elas as Operações Urbanas (OUs). As OUs foram implementadas pela primeira vez na cidade de São Paulo durante a década de 1990, e em 2001, regulamentadas a nível nacional por meio do Estatuto. A regulamentação das OUs em escala nacional serviu para popularizar essa ferramenta para além do município de São Paulo e, principalmente, para introduzir um conjunto de regras mais estável e homogêneo, criando um ambiente seguro e atrativo para possíveis investidores.

No Estatuto da Cidade, as OUs estão definidas nos artigos 32, 33 e 34, que determinam os requisitos legais mínimos para a implementação de parcerias públicoprivadas e a possibilidade de os municípios emitirem títulos adicionais de direitos de construção (CEPACs). Assim, apesar de haver uma estrutura federal que estabelece tais requisitos, todas as OUs são efetivamente implementadas por cada cidade, uma vez que é através de uma lei municipal que uma Operação Urbana é instaurada. Dessa forma, cada cidade é livre para incluir aspectos que julgue necessários.

Embora ainda sejam poucas, as Operações Urbanas estão se tornando cada vez mais populares no contexto brasileiro. São Paulo é a cidade com o maior número de OUs em andamento (atualmente são cinco). Esse instrumento é utilizado, em geral, como uma tentativa de "revitalizar" áreas "abandonadas". Exemplos de OUs em outras cidades são: OU Antônio Carlos/Pedro I Leste - Oeste, em Belo Horizonte; OU Linha Verde, em Curitiba; OU Joana Bezerra, em Recife; e OU Área Central, em Niterói. Atualmente, a Operação Urbana Porto Maravilha (Rio de Janeiro) é a intervenção mais cara e intrincada em curso no país, criando um novo paradigma para projetos desse tipo (Pereira 2015). Das cidades com OUs em curso, apenas três dependem da emissão dos CEPACs: São Paulo, Rio de Janeiro e Curitiba.

As Operações Urbanas foram pensadas como um mecanismo que facilitaria a promoção de PPPs. Apesar desse instrumento ser às vezes tomado como uma "fórmula 
mágica" (Fix 2000) para a requalificação de áreas degradadas, visto que os empreendedores assumiriam os custos da "revitalização"3, deixando o estado livre para investir seus recursos em áreas de menor interesse do mercado. No entanto, os exemplos de OUs já implementadas mostram um retrato bastante diferente na prática. Há muitas críticas sobre a capacidade das OUs realmente melhorarem ambientes urbanos, especialmente para a população que já residia nessas áreas; sobre a real isenção de suporte financeiro público para a execução de obras em diferentes estágios do projeto, visto que projetos como o Porto Maravilha desafiam esse argumento; sobre a existência de uma efetiva parceria entre público e privado, uma vez que em vários casos o estado se comporta como um (se não o único) investidor; e sobre os impactos socioespaciais trazidos por esses projetos, incluindo a gentrificação de áreas centrais, a espetacularização de áreas urbanas, etc. (Fix 2001; Maricato and Ferreira 2002; Mosciaro and Pereira 2019). Sendo assim, as Operações Urbanas na prática e na teoria parecem divergir bastante, visto que a maioria dos benefícios atrelados ao uso desse mecanismo não se mostra presente nos projetos já implementados.

É importante esclarecer que não são todas as OUs que são financeirizadas. O processo de financeirização desses projetos se dá por meio da utilização dos CEPACs como estratégia de financiamento da intervenção. Como já mencionado, apenas três Operações em curso atualmente dependem desses títulos para o seu financiamento. Originalmente, as OUs só sairiam do papel quando agentes privados demonstrassem interesse no projeto por meio da compra de CEPACs. Porém, o exemplo do Rio de Janeiro, que será apresentado em detalhes mais à frente, desafia essa racionalidade.

\section{Programa de Intervenção Integrada}

Diferente das Operações Urbanas, que foram estipuladas inicialmente como uma lei municipal - posteriormente alçada ao nível de legislação federal - e cujos projetos são regulamentados pela prefeitura; na Itália, o ponto de partida para a financeirização de grandes projetos foi dado em nível federal. No caso italiano, a lei versa sobre o tecido urbano e o ambiente construído e determina que atores públicos e privados podem propor projetos de requalificação. Caso esses projetos contrariem determinações urbanísticas pré-estabelecidas (como por exemplo o "plano diretor"), eles podem ainda assim ser aprovados. Dessa forma, o governo federal introduz uma nova regulamentação, que, assim como as Operações Urbanas, permite a criação de espaços de exceção (Vainer 2011), áreas financiadas, planejadas e gerenciadas de maneira excecional.

\footnotetext{
3 A verba arrecadada por meio da venda de CEPACs é utilizada para, dentre outras coisas, promover melhorias infraestruturais que acabam por auxiliar na valorização da área em questão. No caso do Porto Maravilha, além de custear obras como a reestruturação da malha viária, criação de duas novas linhas de Veículo Leve sobre Trilhos, restauração e preservação de símbolos históricos, etc..., pela primeira vez em uma Operação Urbana, a verba também se destina a promoção de serviços urbanos, como limpeza das ruas e manutenção da iluminação urbana por um período de 15 anos.
} 
Em uma época de ascensão do pensamento neoliberal em nível regional e municipal (Bolocan Goldstein and Bonfantini 2007; González 2009), a região da Lombardia, a partir das diretrizes estipuladas pela lei nacional, aprovou em 1999 uma lei que dispõe sobre a implementação dos Programas de Intervenção Integrada (PIIs) em seu território. Essa determinação regional expande e detalha de forma mais precisa como se configuram os PIIs, quais são as suas principais metas e intenções e quais são os procedimentos para a sua implementação. Assim como no caso brasileiro, essas novas determinações facilitaram a propagação de projetos, uma vez que um ambiente seguro e regulado é criado, garantindo a proteção de possíveis investidores. Pogliani (2006) argumenta que os PIIs são o principal instrumento para fomentar a cooperação público-privada no cenário do desenvolvimento urbano e revela que o papel do setor privado cresceu significativamente na determinação de projetos urbanos, inaugurando uma época de "planejamento através de acordos", especialmente em Milão.

Segundo as determinações da região, para se implementar um projeto nos moldes do PII, deve-se desenvolvê-lo detalhadamente em conjunto com a prefeitura local. Portanto, apesar da região ter criado normas para esse instrumento, são as entidades locais que irão, de facto, regulamentar, fiscalizar e negociar caso a caso os projetos a serem implementados em seu território. Gaeta (2007) descreve o processo usual de proposição e aprovação de PIIs em Milão. A primeira etapa é uma reunião informal entre os setores público e privado, um encontro exploratório. Uma vez concluída, o setor privado desenvolve uma proposta inicial (incluindo os volumes esperados e um plano de viabilidade). Em seguida, é feita uma avaliação pelo município para determinar se o projeto pode ser admitido como um PII. Caso isso aconteça, os especialistas encarregados continuam o processo, exigindo então um plano económico-financeiro da intervenção. O perito municipal (aconselhado por um advogado, um urbanista e um economista) é quem negociará com o representante do projeto itens como a quantidade de espaços públicos, as taxas a serem pagas à prefeitura, os responsáveis por custear e realizar as obras públicas, etc. Este funcionário público também será responsável por negociar com outros departamentos do município em nome do projeto. Uma vez que a comissão de construção da cidade for ouvida, uma proposta final poderá ser elaborada. Se a intervenção estiver de acordo com o Piano Regolatore (um equivalente ao plano diretor), a junta pode aprová-lo diretamente. No entanto, se não estiver em consonância com o Piano Regolatore, o projeto deve apresentar um esboço de emendas ao Piano para ser discutido pelo conselho municipal. Ou seja, a discrepância com a regulamentação urbanística, como já mencionado, não necessariamente impede a implementação do projeto, uma vez que emendas podem ser feitas no Piano Regolatore. Idealmente, esse constante contato entre público e privado permitiria que os representantes da sociedade assegurassem os interesses da população frente ao investidor privado. Porém, como foi evidenciado pelos períodos mais intensos da crise dos anos 2000, as municipalidades italianas estão severamente endividadas e em busca de novas fontes de capital (Lagna 2013). Diante 
desse contexto, a capacidade de negociação e barganha do setor público ficou bastante limitada. As cidades se tornam dependentes dos grandes valores gerados por esses projetos, especialmente das taxas de urbanização, estipuladas caso a caso. A verba gerada por esses projetos se tornou nos últimos anos uma grande fonte de renda para os municípios e o caso de Milão é um dos principais exemplos (Mosciaro 2020).

Assim, como no caso das OUs, os PIIs não são necessariamente instrumentos de financeirização por si só. Porém, ao investigar casos específicos em que essa legislação urbanística foi implementada percebe-se como ela pode facilitar a infiltração de agentes financeiros na produção do espaço (Mosciaro 2020; Anselmi 2015). Como veremos na próxima sessão o projeto CityLife se torna um emblemático exemplo de financeirização na cidade de Milão em função dos atores envolvidos e, principalmente, dos objetivos que os levaram a se tornarem produtores imobiliários.

\section{A financeirização das Operações Urbanas e dos Planos de Intervenção Integrados}

A sessão anterior apresentou em linhas gerais no que consistem as OUs e os PIIs. Agora iremos discutir como essas ferramentas de requalificação urbana podem ser compreendidas como dois possíveis caminhos para a financeirização do ambiente construído. Como mencionado previamente, os casos do Brasil e da Itália são mobilizados para enriquecer o debate acerca das formas como racionalidades, instrumentos, atores e narrativas financeiras estão se tornando cada vez mais presentes na governança urbana. Por esse motivo, apresentamos dois mecanismos desenvolvidos localmente e que têm se mostrado importantes alicerces para a financeirização de grandes projetos.

O caso das OUs como suporte para a financeirização do ambiente construído no Brasil já foi bastante debatido na literatura, especialmente os casos paulistas (Fix 2000; Maricato and Ferreira 2002; Mosciaro and Pereira 2019). A relação entre esse mecanismo de planejamento urbano e mercados financeiros é bastante clara e se dá através da emissão de títulos (Certificado de Potencial Adicional de Construção CEPACs) que podem ser adquiridos no mercado primário (através de leilões) e, posteriormente, no mercado secundário (BOVESPA) ${ }^{4}$. Dessa forma, esses títulos nada mais são do que ativos de renda variável, visto que sua rentabilidade está atrelada à valorização dos espaços em questão. Os CEPACs, vendidos para custear os projetos de melhorias urbanas que devem ocorrer dentro da área de intervenção, são apenas uma das muitas maneiras que os governos encontraram para antecipar receitas futuras em uma área com potencial para requalificação (Peterson 2014; Weber 2010), e o seu funcionamento é bastante simples: uma vez definido o perímetro de uma OU, a cidade

4 http://www.b3.com.br/pt_br/produtos-e-servicos/negociacao/renda-variavel/cepac.htm, acessado em 08.07.2020 
pode optar por emitir títulos de construção adicional cuja verba será revertida em melhorias dentro da área do projeto. Resumindo, todo empreendimento que exceder o gabarito ${ }^{5}$ de uma dada área poderá ser construído desde que CEPACs sejam adquiridos. A renda arrecadada com a venda desses títulos custeia obras de infraestrutura (e em alguns casos serviços) a serem realizadas dentro do perímetro da intervenção. É por meio dos CEPACs que se forja a narrativa da "fórmula mágica" - a promoção de melhorias urbanas sem dinheiro público (Fix 2000).

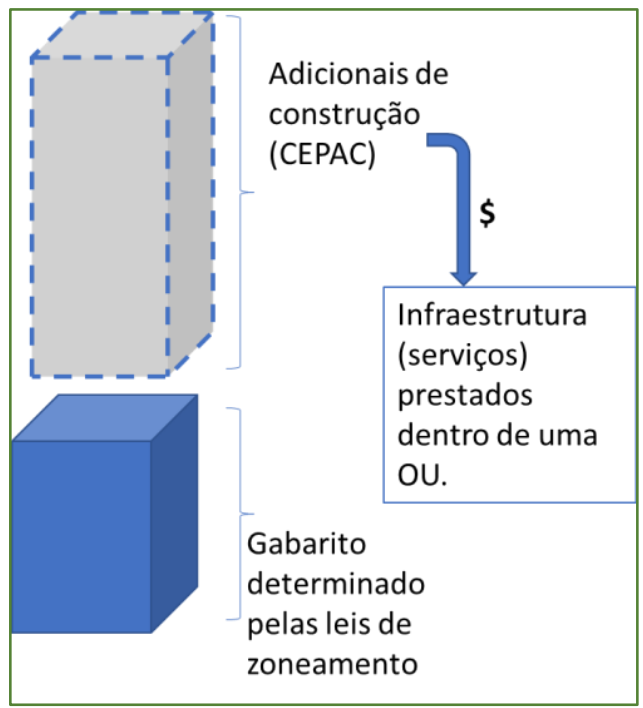

Figura 3: Representação esquemática dos CEPACs

Fonte: Elaboração própria

Atualmente, a maior OU em andamento no Brasil é a Operação Urbana Porto Maravilha, que visa requalificar a região portuária da cidade do Rio de Janeiro. Essa OU emitiu aproximadamente 6,44 milhões de CEPACs, o equivalente a mais de 4 mil $\mathrm{m} 2$ adicionais. Diferente de OUs anteriores, nas quais os CEPACs foram vendidos em múltiplos leilões para inúmeros compradores, nesse caso todo o estoque de títulos foi adquirido por um único comprador e de uma só vez, o Fundo de Garantia do Tempo de Serviço (FGTS). Em termos simples, o FGTS é um fundo paraestatal ${ }^{6}$ composto pela contribuição obrigatória de todos os trabalhadores formais do país. Em um contexto internacional ele pode ser compreendido como um misto entre um fundo de pensão e

5 Gabarito: limite de altura máximo que deve ser respeitado ao se executar uma obra de arquitetura. Esses valores são definidos pela prefeitura e variam de acordo com cada área da cidade. Especificamente no caso do Porto Maravilha os gabaritos variam entre 7,5 e 150 metros, dependendo da zona.

6 Por "paraestatal" compreendemos uma instituição criada pelo Estado, mas que possui administração própria, e cuja atividade é de interesse público. No caso do FGTS essa administração é feita por um conselho curador tripartite composto por seis representantes do governo federal, três dos empregadores e três dos empregados. Essa instituição é bastante peculiar em termos de organização, contribuição e investimentos. O agente operador dos fundos do FGTS é a Caixa Econômica Federal, sendo assim, a poupança compulsória feita por todos os trabalhadores formais do país é gerenciada por um conselho, mas a execução e o gerenciamento do capital são feitos por um banco público. 
um sistema de seguro-desemprego (para uma discussão mais aprofundada sobre o FGTS, Mosciaro and Aalbers 2017).

A existência de uma Operação Urbana não determina categoricamente a financeirização do ambiente construído, esse processo só ocorre nas OUs que dependem da comercialização de CEPACs (Ferreira and Fix 2001; Royer 2016). Nestes casos a financeirização do ambiente construído é clara e incontestável. No entanto, o caso do Porto Maravilha chama a atenção para a financeirização não apenas de uma área restrita dentro da cidade, mas de todo o aparelho estatal, em seus diferentes níveis, que suporta, organiza e financia esse projeto (Pereira 2017; Rolnik 2015). A compra de todos os títulos por um fundo paraestatal, ou semipúblico, demonstra a possível socialização dos riscos desse projeto, afinal, se os CEPACs não forem re-vendidos, são os contribuintes do FGTS que irão arcar com o prejuízo (Rolnik 2015; Royer 2016). Nesse contexto, um órgão que tinha como preceito inicial promover o acesso à casa própria, infraestrutura e saneamento básico, com o intuito de contribuir para cidades mais igualitárias e inclusivas, torna-se o principal agente em um projeto que estimula a concentração de investimentos, exacerbando e consolidando o desenvolvimento desigual (Mosciaro and Pereira 2019). Essa desigualdade se dá uma vez que as áreas selecionadas para receber OUs tendem a ser áreas que já eram de interesse do setor imobiliário e possuíam grande potencial de desenvolvimento e valorização; enquanto áreas menos atrativas e que poderiam se beneficiar dos investimentos e da publicidade gerada por uma Operação Urbana permanecem marginalizadas.

No caso do Porto Maravilha uma situação bastante peculiar foi observada. Todos os CEPACs foram adquiridos pelo FGTS pelo valor de US\$ 2,09 milhões ${ }^{7}$. Nesse montante estavam incluídos todos os títulos emitidos pela OU, gerando um monopólio dos CEPACs nas mãos do fundo. Esse acordo foi aceito pois, para a cidade do Rio de Janeiro, essa era uma forma simples e imediata para assegurar a implementação do projeto; e, para o FGTS, caso o projeto fosse um sucesso, eles teriam total controle da intervenção, o que poderia gerar um retorno financeiro considerável. Atuando desta forma e em uma intervenção desse porte, o FGTS permitiu que o projeto saísse do papel, porém ao mesmo tempo se tornou mais um investidor. A presença do fundo no Porto Maravilha contraria os seus preceitos originais agindo de forma especulativa sobre o espaço urbano, buscando a maximização dos seus lucros, independente dos impactos socioespaciais gerados para concretização dos seus objetivos (Mosciaro et al. 2021).

Neste arranjo, os principais pilares das Operações Urbanas são destruídos. Em primeiro lugar, o fundo paraestatal se torna o principal financiador do projeto, ao invés de deixar a cargo do setor privado, como defendido pelos entusiastas da "fórmula mágica". O FGTS assume riscos desnecessários e que em caso de insucesso, como foi

7 Em Reais (BRL) o investimento do FGTS foi de 3,5 bilhões - o valor em dólares (USD) é convertido considerando-se a cotação média do ano de 2011 , quando a transação foi realizada $(\mathrm{R} \$ 1,67)$. 
recentemente observado ${ }^{8}$, socializa os riscos desse projeto entre todos os trabalhadores formais do país (Rolnik 2015). Neste exemplo o conceito de parceria se torna bastante frágil, visto que o estado se mostra como um prestador de serviços para o setor privado, criando todo o suporte necessário e absorvendo os riscos para assegurar o lucro deste (Mosciaro et al. 2021). Sendo assim, as Operações Urbanas se mostram como uma ferramenta que não apenas facilita a financeirização das cidades, ou pelo menos de algumas áreas dentro das maiores cidades do país, mas também como uma forma de financeirização do estado, que se torna um dos principais agentes na consolidação desses projetos, extrapolando a sua função meramente reguladora.

Já no caso italiano os Programas de Intervenção Integrada por si só não possuem nenhum tipo de mecanismo que imediatamente relacione esse instrumento ao mercado financeiro. No entanto, observando os atores por trás de alguns desses projetos, e em especial o mais recente, CityLife, podemos observar a presença de agentes que assumem o controle sobre a produção da cidade como mais um ativo financeiro. O projeto CityLife já foi detalhadamente discutido (ver Mosciaro 2018 e 2020), porém alguns aspectos devem ser levantados aqui para explicar o que nos leva a afirmar que se trata de um projeto movido por impulsos financeiros e demonstrar que os PIIs são ferramentas fundamentais para a financeirização das cidades italianas.

A transferência da área feirística do centro da cidade de Milão para a sua periferia é um projeto debatido desde os anos 80, porém apenas em meados dos anos 2000 momentum foi criado para que essa transferência se concretizasse. Em uma iniciativa conjunta, a Fondazione Fiera Milano (dona do terreno) em associação com a prefeitura e a região Lombardia organizaram um concurso internacional para selecionar o projeto que seria responsável pela requalificação da antiga Fiera. O projeto ganhador, ou melhor, comprador, era liderado pela empresa de seguros Generali, em associação com a seguradora alemã Allianz e mais duas empresas do ramo imobiliário Italiano (Progestim e Lamaro). Dizemos que esse foi o grupo comprador porque na realidade o concurso tinha uma motivação financeira clara, angariar pelo menos $€ 310$ milhões para os cofres da Fondazione. As características urbanísticas de cada projeto foram um mero detalhe na escolha do consórcio vencedor, visto que o determinante no fim do concurso, como estipulado pelo edital, seria o valor oferecido pela terra, que no caso da Generali foi de 523 milhões de euros. O projeto, que começou a ser implementado em 2004 logo após a compra do terreno, ainda se encontra em fase de implementação. Devido à crise financeira internacional, que atingiu fortemente o mercado italiano em 2009 (Mosciaro 2018), o andamento foi prejudicado e, por isso, o terceiro arranha-céu só foi concluido em 2020. Algumas das unidades habitacionais ainda estão em fase de construção em 2021. Outro PII emblemático na cidade não teve o mesmo destino. O projeto Santa Giulia, liderado por uma das mais importantes construtoras milanesas,

8 https://wwwl.folha.uol.com.br/mercado/2020/06/apos-prejuizo-bilionario-ao-fgts-caixa-diz-querevitalizacao-do-porto-do-rio-e-inviavel.shtml, acessado 17.08.2020. 
foi abandonado depois que a empresa declarou falência no auge da crise econômica (Stefanoni 2014).

Como mencionado por muitos entrevistados, a única razão pela qual o CityLife pode ser concluído se dá "graças" ao envolvimento de empresas de seguros, que podem aguardar por longos períodos de retorno e que não dependem da comercialização das unidades produzidas para atingir as suas metas. Afinal, o intuito primordial do CityLife era criar ativos para compor o portfólio das seguradoras; a ocupação ou o uso desses espaços são elementos secundários no projeto econômico dessas empresas (Mosciaro 2020; van Loon and Aalbers 2017). Em termos de ocupação, o projeto CityLife é um fracasso. Dos 563 apartamentos já construídos, menos da metade havia sido vendido até 2016. Além disso, das três torres de escritório produzidas, duas precisaram ser ocupadas pela própria Generali e pela Allianz, que em uma medida emergencial transferiram todos os seus escritórios espalhados pela cidade para as torres do CityLife?. A terceira torre começou a ser construída em 2016 ainda sem um ocupante em mente, mas em 2018 foi divulgado que a empresa de consultoria PwC alugou o prédio por 24 anos - a propriedade da torre, ainda em construção, provavelmente se mantém com a Generali.

A imagem apresentada neste artigo sobre o CityLife é uma versão muito sintética das complexas negociações e acordos que ocorreram para que esse projeto fosse implementado (para uma descrição detalhada, ver Mosciaro, 2018 e Mosciaro, 2020). No entanto, os aspectos aqui levantados servem para ilustrar a configuração do REFCOM no contexto italiano. Esse projeto é um claro exemplo de que os setores financeiro, de seguros e imobiliário (FIRE - finance, insurance, and real estate, em inglês) estão cada vez mais interligados. Previamente, a indústria financeira e de seguros (FI) investia na aquisição de bens imobiliários (RE), mas a sua produção ficava a cargo de especialistas do setor imobiliário (Bryson 1997). Atualmente, bens imobiliários se tornaram apenas mais uma classe de ativo na carteira dessas empresas (van Loon and Aalbers 2017). Por esse motivo, o fracasso comercial do CityLife não significa que ele seja um fracasso para os acionistas da Generali, uma vez que o principal objetivo das seguradoras (como declarado por seus gerentes e diretores) era renovar os seus portfólios em Milão, tarefa que estará terminada após a construção das unidades habitacionais em execução.

Diferente da Operação Urbana Porto Maravilha, no caso do CityLife a participação da prefeitura se dá de maneira muito discreta, o que não quer dizer que isso seja uma característica positiva. Novamente, a ideia de parceria não consegue se consolidar; neste caso, devido à falta de capital do município, a cidade se torna quase refém da iniciativa privada. Na primeira versão do PII uma série de projetos sociais e culturais

9 O caráter emergencial da ocupação das torres pela Generali e pela Allianz foi um dos aspectos mais debatidos nas entrevistas realizadas em Milão. Apesar de não haver um consenso sobre qual era a intenção inicial das seguradoras (vender imediatamente as torres; manter a propriedade, mas alugar as torres para terceiros, etc.), a decisão de ocupar os prédios jamais esteve no projeto dessas empresas, como atestado pelos diretores de ambas as seguradoras. 
(creche, museu da criança, museu do design) deveriam ser financiados com os €200 milhões pagos pelo consórcio à prefeitura como taxa de urbanização. A intenção era que essas intervenções agregassem à comunidade e à cidade como um todo. No entanto, como identificado por alguns entrevistados, devido à crise, nenhum desses projetos se consolidou porque os fundos foram gastos com serviços básicos da municipalidade, como o pagamento de funcionários e a manutenção de prédios e serviços já existentes. Um aspecto interessante do projeto CityLife é que por se encontrar em uma área relativamente nobre da cidade processos de gentrificação ou exclusão de moradores pré-existentes não constam dentre as demandas sociais associadas a esse projeto (Mosciaro 2018). Em todo caso, diante deste cenário, um dos entrevistados declarou que a grande dependência que a cidade de Milão criou com os PIIs dá a impressão de que a cidade está sendo vendida em pequenos pedaços.

\section{Conclusão}

A discussão do REFCOM nos casos do Brasil e da Itália contribui para a colcha de retalhos dos estudos de financeirização, ajudando a construir uma literatura mais plural sobre o tema, incluindo experiências de "financeirização subordinada" (Büdenbender and Aalbers 2019; Kaltenbrunner and Painceira 2017; Lapavitsas and Powell 2013; Rodrigues, Santos, and Teles 2016). Assim, olhando para esses casos, a primeira avaliação é o reconhecimento de que não se trata de um fenômeno uniforme (Fernandez and Aalbers 2019). Pelo contrário, a financeirização, especialmente do ambiente construído, está amplamente relacionada aos atores, instituições e relações locais e, por isso, é adaptada a cada situação específica. A ideia de um Complexo Imobiliário/Financeiro ajuda a desvendar as diferentes camadas que compõem esses processos, uma vez que examina as conexões entre o estado, o mercado imobiliário e os mercados financeiros. Além disso, apoiando-se em uma análise multiscalar, elucida aspectos relativos à financeirização dos órgãos governamentais nacionais e locais, aos fluxos globais de capital e, também, às repercussões locais de tais relações.

Como discutido ao longo desse artigo, a financeirização do setor imobiliário ocorre de várias formas, mas é representada principalmente pela crescente perceção de que o ambiente construído pode ser usado (construído, reconstruído, destruído), em primeiro lugar, para fins financeiros (Peck and Whiteside 2016; Savini 2017; Weber 2010). Com o intuito de debater a formação do Complexo no Brasil e na Itália, este artigo focou em dois mecanismos de produção/requalificação do ambiente construído que têm facilitado a infiltração de instrumentos e agentes financeirizados nas principais cidades desses países.

Tanto as Operações Urbanas quanto os Programas de Intervenção Integrada são estratégias que surgiram nos anos 90, pautadas pelo discurso da governança urbana neoliberal e do empreendedorismo urbano (Hall and Hubbard 1996; Harvey 1989). Essas ferramentas visavam facilitar a cooperação entre entidades públicas e privadas com o intuito de desafogar os orçamentos públicos e promover uma maior participação de agentes privados na produção do espaço. Porém, assim como outras 
estratégias que visavam o "roll back" do estado, o que se observa é uma reconfiguração da ação das instituições públicas, e não o seu recuo (Aalbers 2016). Em ambos os casos constatamos a presença do estado em diferentes níveis (nacional, regional e municipal) e assumindo diferentes papéis - regulador, financiador, organizador, promotor, etc. Apesar de demonstrarem sistemas organizacionais bastante distintos, especialmente considerando os casos do Porto Maravilha e do CityLife, nos dois as demandas do setor privado prevaleceram. O setor público e seu papel mediador não serviram para assegurar os interesses e reivindicações da população, pelo contrário, as ambições do setor privado e de seus investidores é que foram tranquilizadas e protegidas por diferentes instituições e agências públicas - seja por meio da presença direta do estado como no caso do Porto Maravilha/FGTS; ou, nas recorrentes revisões pelas quais o projeto original do CityLife foi submetido devido aos impactos da crise financeira (Fix 2001; Peck and Whiteside 2016).

O Porto Maravilha e o CityLife são exemplos relevantes porque apresentam processos distintos, que, independentemente de suas peculiaridades, ilustram como as narrativas financeiras estão penetrando no espaço urbano e transformando o ambiente construído. Esses exemplos contribuem não apenas para os debates nacionais sobre a dependência de Operações Urbanas ou Programas de Intervenções Integradas, mas também para uma discussão mais ampla que visa compreender os novos contornos que o planejamento urbano vem adquirindo na era neoliberal (Balducci 2003; Bolocan Goldstein and Bonfantini 2007; Moulaert, Rodriguez and Swyngedouw 2005).

Idealmente, ambos os mecanismos são tentativas notáveis de envolver o setor privado no desenvolvimento urbano, promovendo novos espaços e melhorando a qualidade de vida nas cidades. Tanto as Operações Urbanas quanto os Programas de Intervenção Integrada são ferramentas válidas para promover projetos de requalificação urbana. No entanto, devido à maneira como foram empregadas até agora, seus benefícios sociais mais amplos ainda não foram vistos (Mosciaro 2020; Mosciaro et al. 2021 ). Uma vez que o estado passou a se comportar como um investidor, no caso do Porto Maravilha, ou como um cliente, como visto no CityLife, ele se tornou refém do sucesso dessas iniciativas.

\section{Bibliografía}

Aalbers, Manuel B. 2011. "ERC REFCOM Project." Disponible a: http://ees.kuleuven.be/geography/projects/refcom/project/.

Aalbers, Manuel B. 2015. "The Potential for Financialization." Dialogues in Human Geography 5 (2): 214-19.

Aalbers, Manuel B. 2016. "Regulated Deregulation." En Handbook of Neoliberalism, editado por S. Springer, K. Birch y J. MacLeavy, 563-73. London: Routledge. 
Aalbers, Manuel B. 2017. "Corporate Financialization." En The International Encyclopedia of Geography: People, the Earth, Environment, and Technology, editado por Richardson, D. et al. Oxford: Wiley.

DOI: 10.1002/9781118786352.wbieg0598.

Aalbers, Manuel B., Rodrigo Fernandez. 2019. "Housing Financialization in the Global South: In Search of a Comparative Framework." Housing Policy Debate.

Andreatta, Verena. 2010. Porto Maravilha 6 Casos de Sucesso de Revitalização Portuária. Rio de Janeiro: Casa da Palavra/Instituto Pereira Passos.

Anselmi, Guido. 2015. “I Megaprogetti Immobiliari Nell'epoca Di Finanziarizzazione e Austerity: I Casi Di Milano e Salford." [PhD thesis]. Milano: Universitá Degli Studi Di Milano-Bicocca.

Arrighi, Giovanni. 1994. The Long Twentieth Century: Money, Power, and the Origins of Our Times. New York: Verso.

Balducci, Alessandro. 2003. "Policies, Plans and Projects." DisP - The Planning Review 39 (152): 59-70.

Bellaviti, Paola. 1994. "Publico e Privato, Centrale e Locale Nella Pianificazione 'per Proggetti': Problemi e Opportunità per l'innovazionedelle Politiche Urbanistiche." Torino: Politecnico di Torino.

Bolocan Goldstein, Matteo y Bertrando, Bonfantini. 2007. Milano Incompiuta: Interpretazioni Urbanistiche Del Mutamento. Milano: Franco Angeli.

Britto, Ana Lúcia; Sonaly, Cristina Rezende. 2017. “A Política Pública Para Os Serviços Urbanos de Abastecimento de Água e Esgotamento Sanitário No Brasil: Fi Nanceirização, Mercantilização e Perspectivas de Resistência." Cadernos Metrópole 19 (39): 557-82.

Bryson, John R. 1997. "Obsolescence and the Process of Creative Reconstruction." Urban Studies 34 (9): 1439-58. https://doi.org/10.1080/0042098975501.

Büdenbender, Mirjam. 2017. "New Spaces of Capital: The Real Estate/Financial Complex in Russia and Poland." [PhD thesis]. Leuven: KU Leuven.

Büdenbender, Mirjam; Aalbers, Manuel B. 2019. “How Subordinate Financialization Shapes Urban Development: The Rise and Fall of Warsaw's Służewiec Business District." International Journal of Urban and Regional Research: 1468-2427. https://doi.org/10.1111/1468-2427.12791.

Christophers, Brett. 2015. "The Limits of Financialization." Dialogues in Human Geography 5(2): 183-200.

De Gaspari, Mario. 2010. Malacittà: La Finanza Immobiliare Contro La Società Civile. Milano: Mimesis Eterotopie.

Di Feliciantonio, Cesare. 2016. "Reversing Neoliberal Subjectification. The ReEmergence of Social Movements around Housing and Real Estate in the Metropolitan Areas of Rome and Barcelona." [PhD thesis]. Rome: Università di Roma (Sapienza) y KU Leuven.

Engelen, Ewald. 2008. "The Case for Financialization." Competition \& Change 12 (2): $111-119$. 
Fairbairn, Madeleine. 2015. "Reinventing the Wheel? Or Adding New Air to Old Tires?" Dialogues in Human Geography 5 (2): 210-13.

Fernandez, Rodrigo. 2017. "Stylized Facts from Housing and Finance: How Do They Relate across Space and Time?" FINGEO - Working Papers Series 1. Disponible en: http://www.fingeo.net/wordpress/wp-content/uploads/2017/07/WP1_Stylizedfacts-from-housing-and-finance-1.pdf.

Fernandez, Rodrigo; Aalbers, Manuel B. 2016. "Financialization and Housing: Between Globalization and Varieties of Capitalism." Competition and Change 20 (2): $71-88$.

Fernandez, Rodrigo; Aalbers, Manuel B. 2019. "Housing Financialization in the Global South: In Search of a Comparative Framework." Housing Policy Debate: 1-22. https://doi.org/10.1080/10511482.2019.1681491.

Ferreira, João SW; Fix, Mariana. 2001. "A Urbanização e o Falso Milagre Do CEPAC." Folha de S. Paulo 17.

Disponible en:

http://www.fau.usp.br/depprojeto/labhab/biblioteca/textos/ferreira_cepacfalsomila gre.pdf.

Fix, Mariana. 2000. “A Fórmula Mágica Da Parceria Publico-Privada: Operações Urbanas Em São Paulo." Cadernos de Urbanismo 3.

Fix, Mariana. 2001. Parceiros Da Exclusão: Duas Histórias Da Construção de Uma Nova Cidade Em São Paulo. São Paulo: Editora Boitempo.

Gaeta, Luca. 2007. “Urbanistica Contratuale. Prassi e Legittimità Nelle Scelte Di Piano." En Milano Incompiuta: Interpretazioni Urbanistiche Del Mutamento, editado por Bolocan Goldstein and Bonfantini ,1 13-27. Milano: FrancoAngeli.

González, Sara. 2009. “(Dis)Connecting Milan(Ese): Deterritorialised Urbanism and Disempowering Politics in Globalising Cities." Environment and Planning A 41: 31-47.

Hall, Tim; Hubbard, Phil. 1996. "The Entrepreneurial City: New Urban Politics, New Urban Geographies?" Progress in Human Geography 20 (2): 153-74.

Harvey, David. 1989. "From Managerialism to Entrepreneurialism: The Transformation in Urban Governance in Late Capitalism." Geografiska Annaler, B (71): 3-17.

Hofman, Annelore. 2017. "The Real Estate/Financial Complex in the United Kingdom and the United States." [PhD thesis]. Leuven: KU Leuven.

Ioannou, Stefanos; Wójcik, Dariusz. 2018. "On Financialization and Its Future." Environment and Planning A. https://doi.org/10.1177/0308518X18820912.

Kaltenbrunner, Annina; Painceira, Juan Pablo. 2017. "Subordinated Financial Integration and Financialisation in Emerging Capitalist Economies: The Brazilian Experience." New Political Economy.

https://doi.org/10.1080/13563467.2017.1349089. 
Kantor, Paul; Savitch, H.V. 2005. "How to Study Comparative Urban Development Politics: A Research Note." International Journal of Urban and Regional Research 29 ( 1 ): 135-51.

Lagna, Andrea. 2013. “Deriving a Normal Country: Italian Capitalism and the Political Economy of Financial Derivatives." Sussex: University of Sussex. Disponible en: http://sro.sussex.ac.uk/47062/1/Lagna,_Andrea.pdf.

Lake, Robert W. 2016. "The Subordination of Urban Policy in the Time of Financialization." En Urban Policy in the Time of Obama, editado por J. De Filippis, 45-64. Minneapolis: University of Minnesota Press. Disponible en:

https://www.academia.edu/14690527/The_Subordination_of_Urban_Policy_in_the_ Time_of_Financialization.

Lapavitsas, Costas; Powell, Jeff. 2013. "Financialisation Varied: A Comparative Analysis of Advanced Economies." Cambridge Journal of Regions, Economy and Society 6: 359-79.

Loon, Jannes van. 2017. "The (Non-) Financialization of Urban Development in the Low Countries." [PhD thesis]. Leuven: KU Leuven.

Loon, Jannes van; Aalbers, Manuel. 2017. "How Real Estate Became 'Just Another Asset Class': The Financialization of the Investment Strategies of Dutch Institutional Investors." European Planning Studies 25(2): 22 1-40.

Maricato, Erminia; S.W. Ferreira, João. 2002. "Operação Urbana Consorciada: Diversificação Urbanística Participativa Ou Aprofundamento Da Desigualdade?" En Estatuto Da Cidade e Reforma Urbana: Novas Perspectivas Para as Cidades Brasileiras. Porto Alegre: S. A. Fabris. Disponible en:

http://cidadesparaquem.org/textos-acadmicos/2002/7/1/operao-urbanaconsorciada-diversificao-urbanstica-participativa-ou-aprofundamento-dadesigualdade.

Mosciaro, Mayra. 2018. The Real Estate/Financial Complex: The cases of Brazil and Italy [PhD thesis]. Milano: Politecnico di Milano and KU Leuven.

Mosciaro, Mayra. 2020. "Selling Milan in pieces: The finance-led production of urban spaces". European Planning Studies.

https://doi.org/10.1080/09654313.2020.1735309

Mosciaro, Mayra.; Aalbers, Manuel. B. 2017. "Asset-based welfare in Brazil." Housing Studies. http://dx.doi.org/10.1080/02673037.2017.1364712

Mosciaro, Mayra.; Pereira, Alvaro. 2019. "Reinforcing uneven development: The financialization of Brazilian urban redevelopment projects". Urban Studies, 56(10): 2160-2178. https://doi.org/DOI: 10.1177/0042098019829428

Mosciaro, Mayra.; Pereira, Alvaro.; Aalbers, Manuel. B. 2021. “The Financialization of Urban Redevelopment: Speculation and public land in Porto Maravilha, Rio de Janeiro." En The Speculative City, editado por Chu and He. Toronto: University of Toronto Press. 
Moulaert, Frank; Rodriguez, Arantxa; Swyngedouw, Erik. 2005. The Globalized City: Economic Restructuring and Social Polarization in European Cities. Oxford: Oxford University Press.

Peck, Jamie. 2015. "Cities beyond Compare?" Regional Studies 49 (1): 160-82.

Peck, Jamie; Whiteside, Heather. 2016. "Financializing Detroit." Economic Geography 92 (3): 235-68.

Pereira, Alvaro. 2015. "Intervenções Em Centros Urbanos e Conflitos Distributivos: Modelos Regulatórios, Circuitos de Valorização e Estratégias Discursivas." [PhD thesis]. São Paulo: Universidade de São Paulo.

Pereira, Alvaro. 2017. "The Financialization of Housing: New Frontiers in Brazilian Cities." International Journal of Urban and Regional Research.

Peterson, Sarah Jo. 2014. "Tax Increment Financing: Tweaking TIF for the 21st Century." Urban Land Magazine. Disponible a:

http://urbanland.uli.org/economy-markets-trends/tax-increment-financingtweaking-tif-21st-century/.

Pogliani, Laura. 2006. "Pianificare per Accordi in Lombardia: Innovazioni al Bivio Tra Deregolamentazione e Responsabilità Negoziale." En Lo Scambo Leale: Negoziazione Urbanistica e Offerta Privata Di Spazzi e Servizi Pubblici, editado por Fausto Curti. Roma: Officina Edizioni.

Robinson, Jennifer. 2010. "Introduction to a Virtual Issue on Comparative Urbanism." International Journal of Urban and Regional Research 35 (1): 1-23.

Rodrigues, João; Santos, Ana C; Teles, Nuno. 2016. A Financeirização Do Capitalismo Em Portugal. Coimbra: Actual.

Rolnik, Raquel. 2015. A Guerra Dos Lugares: A Colonização Da Terra e Da Moradia Na Era Das Finanças. São Paulo: Boitempo.

Royer, Luciana. 2016. "O FGTS e o Mercado de Títulos de Base Imobiliária: Relações e Tendências." Cadernos Metrópole 18 (35): 33-51.

Sanfelici, Daniel de Mello. 2013. “A Metrópole Sob o Ritmo Das Finanças: Implicações Socioespaciais Da Expansão Imobiliária No Brasil." São Paulo: Universidade de São Paulo. Disponible a: http://www.teses.usp.br/teses/disponiveis/8/8136/tde07012014-093205/en.php.

Savini, Federico. 2017. "Planning, Uncertainty and Risk: The Neoliberal Logics of Amsterdam Urbanism." Environment and Planning A 49 (4): 857-75. https://doi.org/10.1177/0308518X16684520.

Stefanoni, Franco. 2014. Le Mani Su Milano: Gli Oligarchi Del Cemento Da Ligresti All'Expo. Milano: Laterza.

Vainer, Carlos. 2011. "Cidade de Exceção: Reflexões a Partir Do Rio de Janeiro." En XIV Encontro Nac. ANPUR 14. Rio de Janeiro. Disponible en: https://br.boell.org/sites/default/files/downloads/carlos_vainer_ippur_cidade_ de_excecao_reflexoes_a_partir_do_rio_de_janeiro.pdf. 
Vainer, Carlos. 2014. "Disseminating 'Best Practice'? The Coloniality of Urban Knowledge and City Models." En The Routledge Handbook on Cities of the Global South, editado por S. Parnell y S. Oldfield. London: Routledge.

Weber, Rachel. 2010. "Selling City Futures: The Financialization of Urban Redevelopment Policy." Economic Geography 86 (3).

Wijburg, Gertjan. 2018. "The Differential Impact of Real Estate Financialization on the Political Economies of Germany and France." [PhD thesis]. Leuven: KU Leuven. Zhang, Yunpeng. 2018. “Grabbing Land for Equitable Development? Reengineering Land Dispossession through Securitising Land Development Rights in Chongqing." Antipode 50 (4): 1120-40. https://doi.org/10.1111/anti.12390

(c) Copyright: Mayra Mosciaro, 2021

(c) Copyright: Scripta Nova, 2021.

Ficha bibliográfica:

MOSCIARO, Mayra. O complexo imobiliário/financeiro no Brasil e na Itália: ferramentas para a produção financeirizada do espaço urbano. Scripta Nova. Revista Electrónica de Geografía y Ciencias Sociales. Barcelona: Universitat de Barcelona, vol. 25, Núm. 1 (2021), p. 83-105 [ISSN: 1138-9788]

DOI: $10.1344 / \mathrm{sn} 2021.25 .32249$ 